\title{
European Invertebrate Charter
}

Once again the Council of Europe has shown perspicacity in the priority area of Nature conservation, coming out unequivocally in favour of invertebrate animals. With Recommendation $\mathbf{N}^{*} \mathbf{R}(86) 10$, its Committee of Ministers adopted the Charter on Invertebrates, which among other things states: 'No animal or plant species must be allowed to disappear because of man's activities'.

Invertebrates constitute the living basis that is needed for regulating the preservation of the wealth of animal and vegetable life, including Man and his activities. Thus many invertebrates are extremely important for human nutrition, and for industry and crafts (for example: marine and terrestrial molluscs and crustaceans), while soil arthropods are essential for humus formation, for the recycling of organic matter, and for soil fertility. They are very important also for scientific and medical research, and as a source of medicinal substances.

Some eighty per cent of the plants cultivated by Man are fertilized by pollinating insects, and we would have little or no food, textile fibres, or medicines, were it not for those insects. On the other hand, $98 \%$ of insect species that are potentially harmful to plants are kept under control by other insects and arthropods: they are in effect a living, natural, permanent, non-polluting, and free, means of protecting plants and due ecological balance.
The Charter acknowledges that, clearly, certain invertebrates may at times be harmful, and recommends that the defence of human interests be rigorously taken into account in seeking to control such excesses. But the active defence of invertebrates has now become necessary also in the interests of Mankind, as is demonstrated by the enormous decrease in invertebrate numbers caused by chemical products indiscriminately discharged into the environment, and by the impairment and destruction of terrestrial and aquatic habitats. The novelty of its concepts and its practical implications make the Charter on Invertebrates a real, and unexpected, cultural revolution.*

Mario Pavan, Professor of Entomology

Department of Zoology

University of Pavia

27100 Pavia

Italy; formerly Chairman, European

Committee for the Conservation of

Nature and Natural Resources.

* Further details-in English, French, German, Greek, Italian, Dutch, Norwegian, Portuguese, Spanish, and Turkish-may be obtained from the European Information Centre for Nature Conservation, Boîte postale 431 R 6, F-67006 Strasbourg Cedex, France. $-\mathrm{Ed}$

\section{Protection of the Chilean Conure or Burrowing Parrot}

As part of Chile's Pehuenche Hydroelectric Project, the World Bank is aiding the financing of a national environmental programme designed to protect the Chilean Conure.* This large and prized bird is the only entirely Chilean Parrot. The Chilean Conure became so rare-hunted for domestication - that about five years ago it was formally protected by the Chilean Government.

About 2,800 Chilean Conure individuals were counted in 1984. The two main pressures on the parrot, capture of the young for commerce, and killing of adults eating crops (maize and wheat), are being addressed by the Government. The critically weak link in the parrot's life-cycle is its habit of breeding only in specific types of vertical cliffs for up to four months (November through February) of each year. The cliffs must have layers or strata soft enough for the bird to excavate a breeding hole one metre or so deep. Rodents and other predators would eat the young in any hole that was not on a perpendicular surface. This Parrot had been eliminated from all but twelve breeding sites (Loureiros) by 1983.

The Pehuenche Hydroelectric Project consists of the construction of a 500-MW power-plant in the Maule River some $250 \mathrm{~km}$ south of Santiago, the construction of an associated transmission system, the formulation of hydropower sector regulations, and technical, financial, and organizational, training. According to World Bank docu- ments, the project is fundamental to meeting Chile's power-sector growth demand after 1982.

Because the reservoir of the Pehuenche Hydroelectric Project will drown two of the nation's twelve remaining breeding sites, the national environmental programme is the main part of the planned mitigatory measures. As the World Bank cannot assist with projects causing the extinction of species, the programme includes the numbered components indicated in the footnote. ${ }^{*}$

\section{RoBert J.A. GOODLAND}

Office of Environmental and Scientific Affairs The World Bank

$1818 \mathrm{H}$ Street, $\mathrm{NW}$

Washington

DC 20433, USA.

\footnotetext{
* Cyanoliseus patagonus byroni, also called the Burrowing Parrot or Greater Patagonian Conure, and Tricahue or Loro Barranquero Chileno in Spanish. The programme includes: (1) Protection of all currently-used breeding sites during the breeding season, including fencing and one manned camp each for 90 days; (2) Capture of parrots from the two sites to be inundated and their re-installation in recently abandoned breeding sites, including 5 years' feeding with collected wild fruits; (3) Support for the captive breeding and the re-introduction programmes, and (4) Support for education and surveillance programmes.
}

\section{Multidisciplinary Assessment of Environmental Risks for Human Health: Summer School in Italy}

The University of Siena, Italy, is organizing a 2-weekslong 'Summer School for Multidisciplinary Assessment of Environmental Risks for Human Health', lasting from Monday 7th until Saturday 19th of September 1987.

Food, lodging, and travel expenses, will be provided for 15 Italian students; food, lodging, and part of their travel expenses, will be provided for 15 foreign students. A degree in Medicine or Biology is normally required of applicants, but holders of degrees in related fields will also be consi- dered. The official language of the Summer School will be English. For further information please contact the undersigned:

\author{
Aristeo Renzoni, Professor \& Chairman \\ Summer School \\ Dipartimento Biologia Ambientale \\ Via delle Cerchia 3 \\ 53100 Siena, Italy.
}

